\title{
Las edades de la piel en la pintura
}

The ages of skin through art

\section{César Iván Varela-Hernández}

Médico dermatólogo; profesor, Sección de Dermatología, Departamento de Medicina Interna, Facultad de Salud, Universidad del Valle, Santiago de Cali, Colombia.

\section{RESUMEN}

El arte y la medicina han permanecido ligados desde tiempos inmemoriales por estar intrínsecamente relacionados con el hombre y su existencia, como puede deducirse de las múltiples obras artísticas y, de manera muy especial, de la pintura. Desde muy temprano y a lo largo de la historia, los pintores han dejado plasmadas en sus producciones las características de la piel y sus cambios durante la vida y, por supuesto, muchas enfermedades -en especial, las dermatológicas por ser la mayoría-, visibles y palpables.

Muchos médicos en diferentes latitudes, interesados en el permanente proceso de culturización, han realizado importantes trabajos en búsqueda de las manifestaciones de la piel en la pintura, y presento este artículo como un aporte a ese propósito, enfocado en los aspectos fisiológicos de la piel, sus cuidados y los cambios en ella producto del correr del tiempo y de factores externos.

PALABRAS CLAVE: piel, dermatología, arte, pintura

\section{SUMMARY}

Art and medicine have been bounded since the beginning of time for being intrinsically related to men and its existence, as it can be deduced from the multiple artistic works, especially paintings. Since very early in time and through history, artists have reflected in their art pieces the skin characteristics and its changes through life, as well as dermatological illnesses due to the fact that the majority of them are visible. Multiple doctors from different places who have been interested in the permanent process of acculturization have done important works in the search of skin manifestation in art. I present this article as a contribution towards that purpose, focusing in the physiological aspects of the skin, the cares that it needs and the changes in skin caused by time and external factors.

KEY WORDS: Skin, dermatology, art, painting

\section{Correspondencia:}

César Iván Varela-Hernández

\section{Email:}

cesar.varela@correounivalle.edu.co

civareladermatologo@hotmail.com

Recibido: 09/02/2017

Aceptado: 22/03/2017

Conflictos de interés:

No se reportan conflictos de interés.

\section{Financiación:}

Ninguna. 
El arte y la ciencia médica se nutren de un fondo común cual es el humanismo, y los dos han contribuido de manera significativa al desarrollo de la humanidad en todos los ámbitos; por ello, su relación resulta interesante y aporta al crecimiento intelectual del Homo sapiens y, de manera particular, al de los médicos y los artistas.

Llamo la atención, en especial de los colegas más jóvenes, sobre la piel sana y la presencia de las enfermedades dermatológicas en la pintura y, desde luego, del arte como un aporte al proceso de culturización continua que los médicos debemos tener, para intentar contribuir a mantener el papel preponderante y diferenciador en la sociedad, como históricamente lo ha tenido, pero que se ha perdido en los últimos tiempos por diversas razones. Traigo a colación el célebre pensamiento de José de Letamendi y Manjarrés: "Del médico que no sabe más que medicina, ten por cierto que ni medicina sabe" 1 .

No pretendo sentar cátedra sobre la historia de la dermatología en la pintura ni sobre la historia de la pintura en la dermatología, ni tampoco hacer un análisis crítico de las obras de arte, ¡ni mucho menos! Eso queda para los estudiosos de semejantes complejidades. Es tan sólo el inicio de una serie de artículos que pretendo presentar, producto del análisis de pinturas en búsqueda de representaciones de la piel normal y sus cambios a lo largo del tiempo, detalles anatómicos y de enfermedades, en textos, revistas y diversas publicaciones, y de observaciones personales en museos.

Varias artes han reflejado en sus expresiones di- versas dolencias del hombre, pero es la pintura la que más testimonios impresionantes y fieles de las enfermedades ha dejado, de manera muy particular de las dermatológicas, por estar la mayoría de ellas a la vista².

El manto desnudo sano e indemne que envuelve los secretos del humano, ha llevado al artista a plasmarlo en sus creaciones, como de manera casi celestial Miguel Ángel lo hizo en La creación de Adán en la bóveda de la Capilla Sixtina (figura 1). Esta obra pictórica incomparable, en donde Dios, como un poderoso anciano, estira su brazo derecho hacia el izquierdo de Adán, sin tocarlo, para infundirle vida, en idénticas posiciones como representando la creación a su imagen y semejanza, en cuanto el brazo izquierdo del Hacedor está alrededor de Eva, aun en los cielos. La perfección de la piel, la musculatura y la proporcionalidad de Adán son seguramente fruto de la experiencia en anatomía del autor. Más allá de la piel, Frank Lynn Meshberger en 1990, publicó en JAMA un análisis del manto rojo donde se encuentra Dios, que puede representar al cerebro humano, incluyendo la hipófisis y el cerebelo ${ }^{3}$.

Infinidad de obras pictóricas conforman una gran galería artística sobre la piel del hombre, desde el manto en formación en la calidez fusca del claustro materno, la vitalidad independiente al alentar, por vez primera, los cambios fisiológicos del recorrido por la vida, la influencia del medio ambiente y de la vida misma hasta llegar al ocaso irremediable, y en ese tránsito, por supuesto, muchas de las dolencias que pueden aquejar al más extenso y vital de los órganos.

Figura 1. La creación de Adán, Miguel Ángel, 1511. Capilla Sixtina, Ciudad del Vaticano

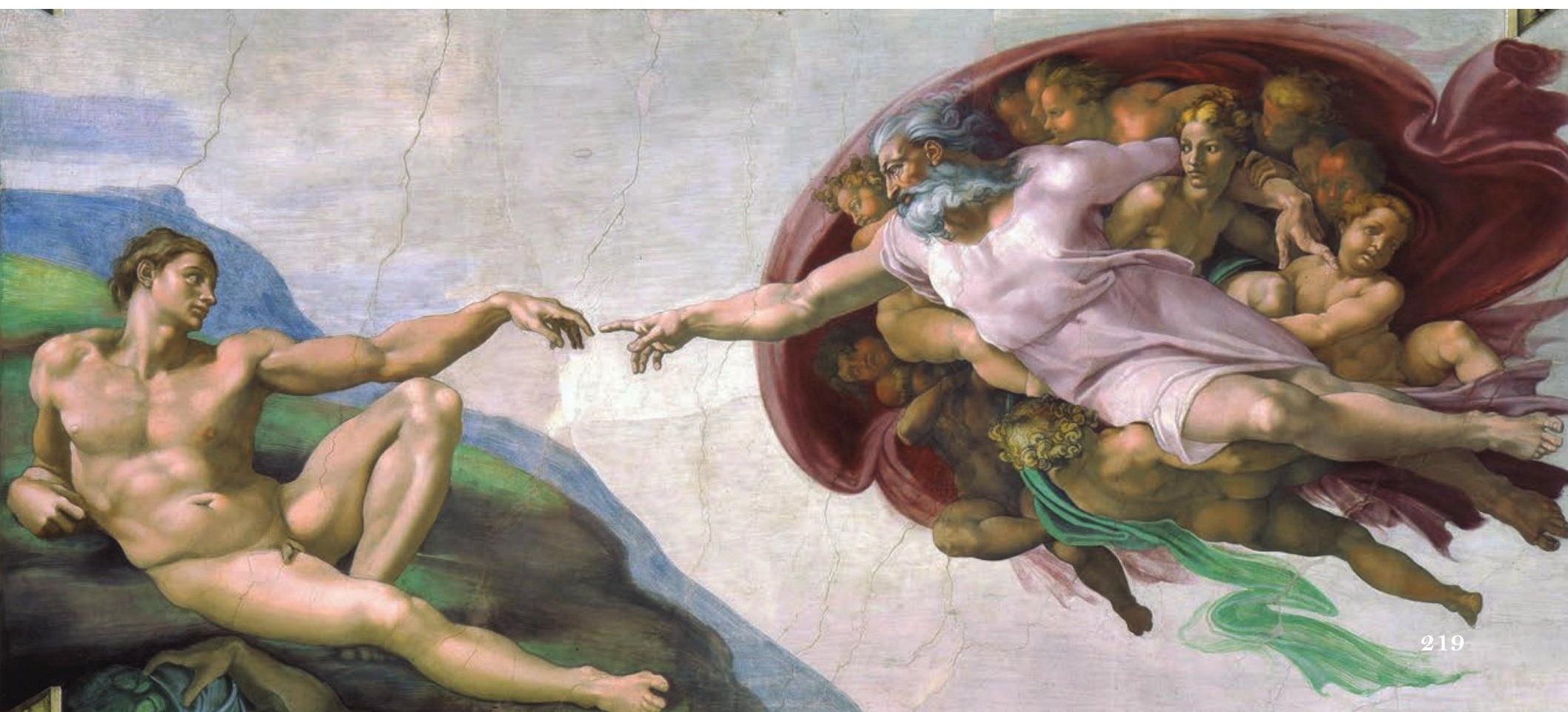


Desde la remota prehistoria hasta el hoy, el hombre, de una $u$ otra forma, por uno $u$ otro motivo, o sin él, ha impregnado con diversos materiales diferentes elementos para dejar allí testimonio de la piel. El pintor, tal vez sin intención, va dejando en el tiempo un legado valiosísimo a la historia de la dermatología y, claro está, a la del arte.

Entre las abundantes imágenes animalísticas que los cazadores prehistóricos dejaron caladas en las taciturnas cuevas, se presentan figuras antropomórficas y los primeros escasos trazos sobre la piel, como las Manos de Altamira en la Cantábrica Santillana del Mar (figura 2), y, las llamadas, quizá inadecuadamente, Manos con falanges amputadas, de las grutas de Gargas en los Pirineos franceses (figura 3). Las manos en negativo y en colores negro y rojo - mezcla de manganeso y óxido de hierro- con aparentes amputaciones de falanges, pueden representar traumatismos por rituales, accidentes o por congelación, o bien, tratarse de simbolismos; datan de, por lo menos, 27.000 años.

Los egipcios (s. XXXI-I a. C.) utilizaron cosméticos obtenidos de sustancias vegetales, piedras, tierra y minerales para protegerse del intenso sol y de la arena, para realzar la belleza y para diferenciarse según la clase social. Tanto en los murales como en los papiros, pintaron la piel, generalmente de color marrón -la de los hombres más oscura que la de las mujeres-, como se aprecia en Horemheb, último faraón de la dinastía XVIII .

En China, la pintura, que inicialmente se realizó

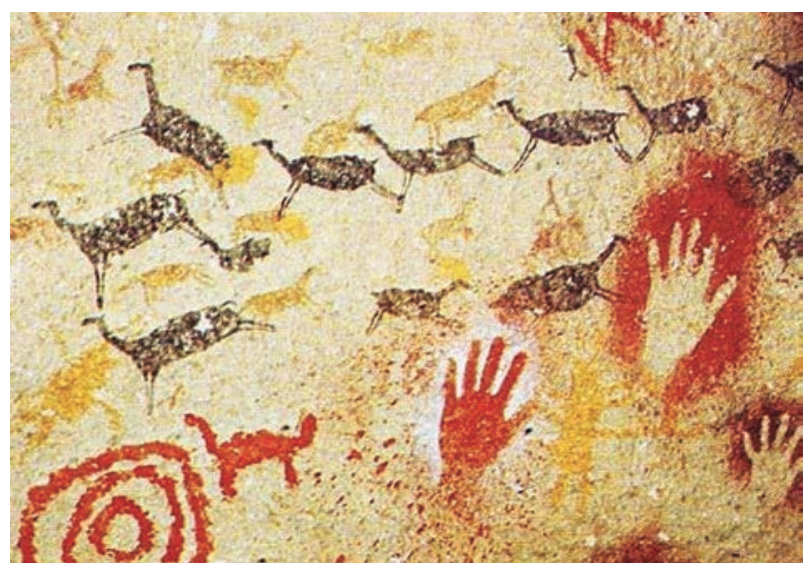

Figura 2. Manos de Altamira. Cueva de Altamira, Santillana del Mar, España

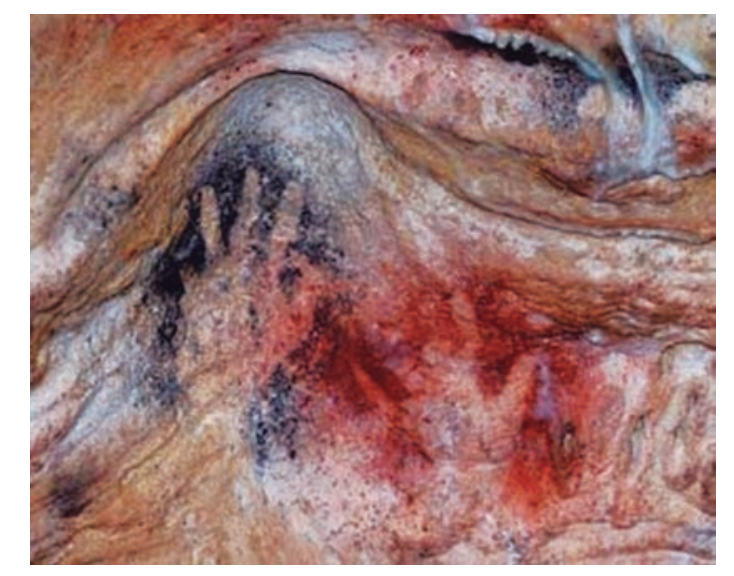

sobre seda, se llevó al papel de arroz con su invención en el siglo I a. C. Si bien es cierto que pocos detalles pueden observarse en las múltiples obras, allí dejó plasmada esta antigua civilización la belleza de la piel, como en Admoniciones de las institutrices del Palacio de las Damas que atesora el Museo Británico (figura 4).

El mayor número de pinturas con detalles de la piel y sus anexos se encuentra a partir de la Edad Media y, de manera especial, en la Edad Moderna con el advenimiento del humanismo y el esplendor de las artes, cuando germinaron pinceles inconmensurables que dejaron su huella in saecula saeculorum, como Leonardo, Rafael, Mantegna, Durero..., con especial dedicación por el retratismo, condición que les permitió plasmar con fidelidad los rasgos normales del tegumento y muchas de las alteraciones cutáneas ${ }^{4}$. En el pasado más reciente, también ha dejado la piel su huella en los lienzos, como en los de Klimt, claro está, conforme con los estilos de pintar más modernos, y en el presente, el hiperrealismo extraordinario en los de Allysa Monks.

\section{CUIDADOS DE LA PIEL}

La naturaleza provee cuidados a la piel desde el embarazo, estructuras que protegen, líquidos, tibieza, transmisión de sentimientos y sonidos arrulladores, como bien lo ilustró Jacques Fabien Gautier d'Agoty en Anatomie des parties de la génération de l'homme et de la femme, en el siglo XVIII en París (figura 5).

Figura 3. Manos con falanges amputadas. Grutas de Gargas, Pirineos, Francia 


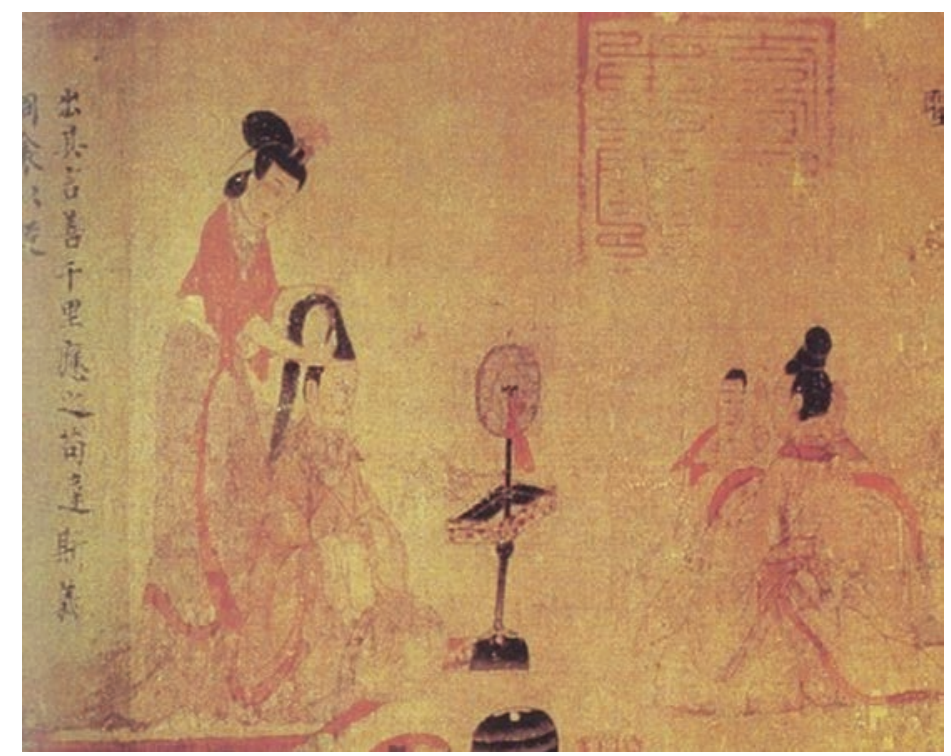

Figura 4. Admoniciones de las institutrices del Palacio de las Damas (detalle), copia de la Dinastía Tang. Museo Británico, Londres

El cuidado de la piel y sus anexos no es novedad del presente ni un comportamiento esnobista. Es probable que desde los inicios de los tiempos, por ser visible y palpable, los primeros homínidos ya diesen algunos cuidados a la piel.

En Egipto, por ejemplo, puede ello deducirse de las imágenes en los papiros, cuidando de las manos, los pies y de las uñas y, más adelante, Evrard d'Espinques, pintor miniaturista francés de la época de Luis XI, dejó en uno de los primeros libros ilustrados de divulgación científica, en la imagen de El baño medicinal, la utilidad del agua sobre la piel (figura 6).

El agua, el elemento natural más cercano y abundante, con el que el hombre ha encontrado desde épocas pretéritas la manera de limpiar y cuidar la piel, de tratar enfermedades e, inclusive, de buscar la eterna juventud, como nos lo recuerda Lucas Cranach, el Viejo, en el primoroso óleo La fuente de la eterna juventud, que pintó en 1546 (figura 7).

La hermosa escena presenta a varias ancianas que, por sus vestimentas y formas de llegar, se puede intuir que son de diferentes niveles sociales; ingresan a la fuente por el lado izquierdo y, en la medida que avanzan y se bañan en sus aguas, su piel y su aspecto se van transformando para salir rejuvenecidas por el lado derecho, donde son recibidas por apuestos caballeros e invitadas a disfrutar de banquetes y bailes. Siempre el hombre ha querido rejuvenecer; hoy, los médicos intentamos continuar haciéndolo con medicamentos, procedimientos y cirugías. El pasado, el presente y el

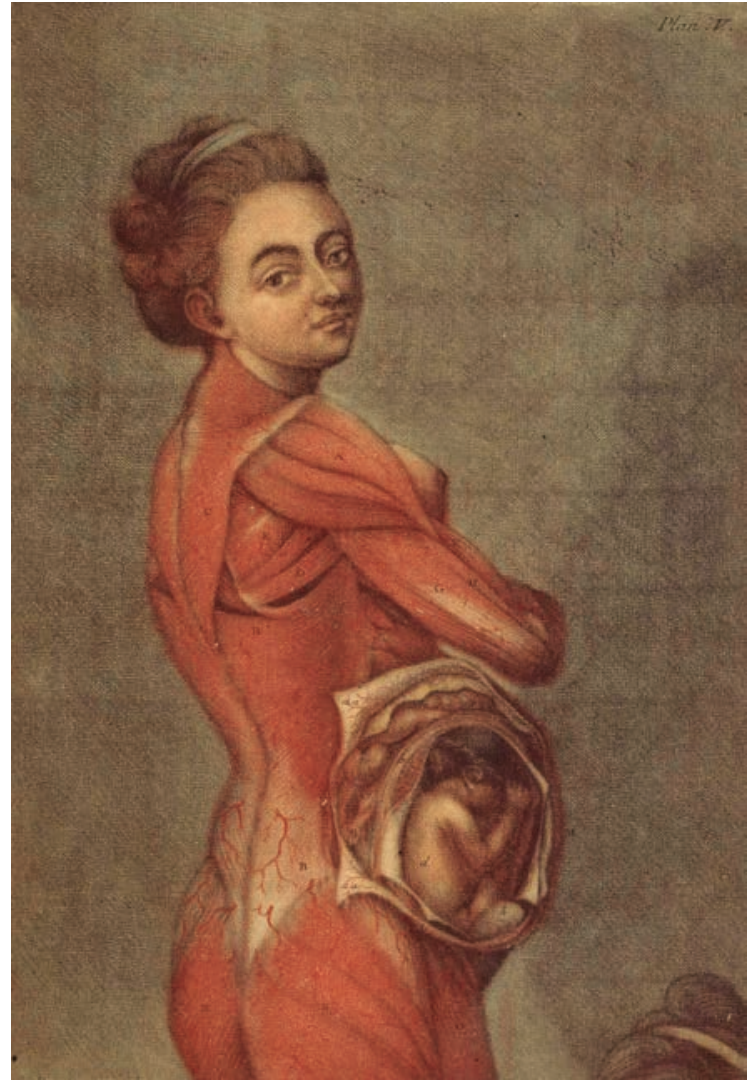

Figura 5. Ilustración anatómica de una mujer embarazada,Jacques Fabien Gautier d'Agoty, 1773. United States National Library of Medicine, Bethesda, MD, USA. 


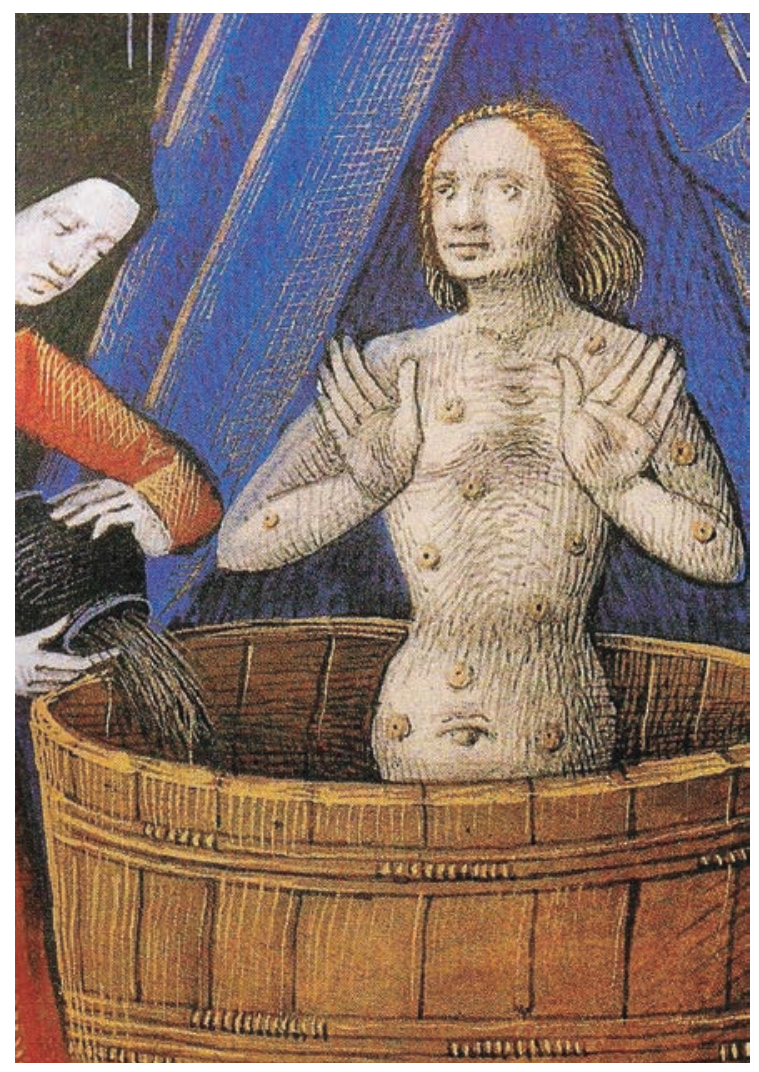

Figura 6. El baño medicinal (detalle), Evrard d'Espinques en: Barthélémy l’Anglais, Des propriétés des choses. Biblioteca Nacional de Francia, París, Francia futuro se funden en el mismo objetivo: mantener o prolongar la juventud y la sanidad.

Cornelisz van Haarlem, en Betsabé en el baño, nos presenta el delicado y complaciente cuidado que las criadas dan en las cristalinas aguas a la bíblica futura mujer del poderoso David ${ }^{5}$,exhibido en el Museo Nacional de Âmsterdam, en donde, además, se aprecia el hermoso contraste del color de porcelana de la piel de Betsabé con el ébano de su bella criada (figura 8); y unas décadas más adelante, en 1634, el gran Rembrandt, en su composición Historias de Diana, nos dejó los puros manantiales que sirvieron de escenario para los idílicos encuentros de las ninfas y Diana cuidando de sus pieles con el agua, atesorado en el Museo Wasserburg Anholt (figura 9).

\section{DEVENIR FISIOLÓGICO DE LA PIEL}

El perfecto manto de la vernix caseosa que cubre con nobleza y generosidad durante las últimas lunas de la gestación la delicada piel del neonato, lo destaca magistralmente la estadounidense Alyssa Monks en Baptism,obra con hiperrealismo extraordinario que por sí sola lo dice todo sobre el tegumento fresco (figura 10).

La piel, su brillo rozagante, turgencia y tersura, son recreados finamente por los grandes pinceles del

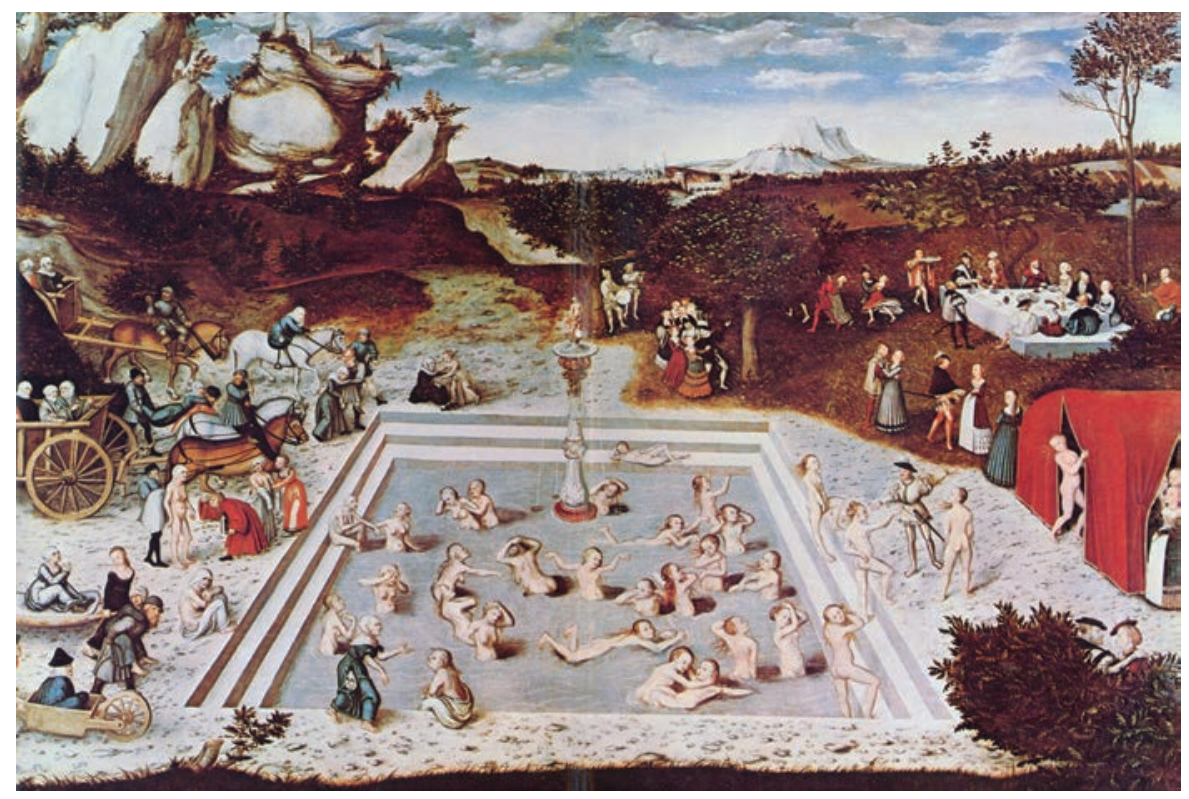

Figura 7. La fuente de la juventud, Lucas Cranach el Viejo, 1546. Museos Estatales de Berlín, Berlín, Alemania 

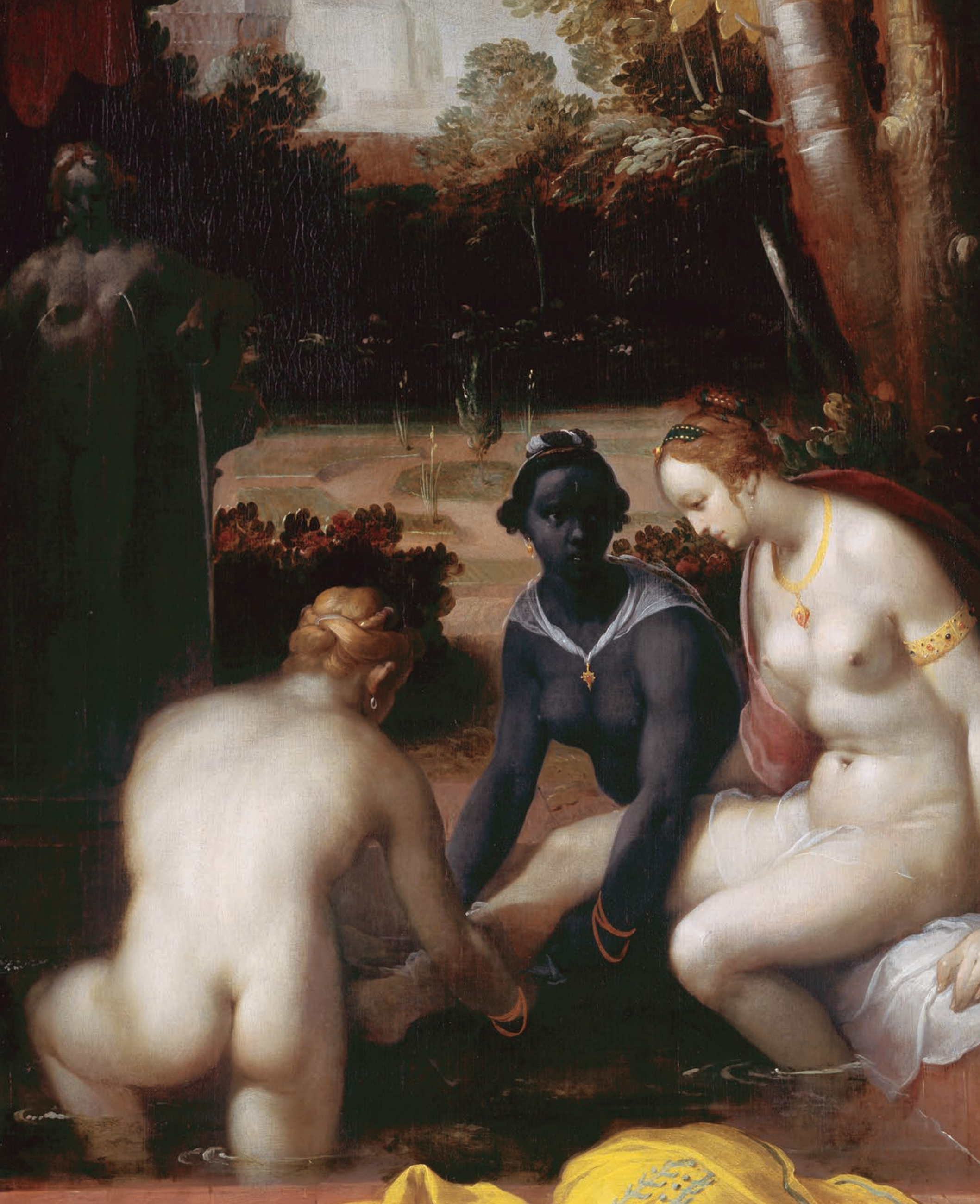

Figura 8. Betsabé en su baño, Cornelisz van Haarlem, 1594. Rijksmuseum (Museo Nãcional de Ámsterdam), Ámsterdam, Holanda

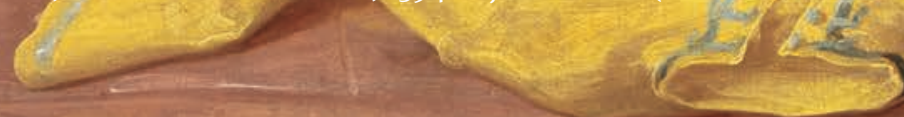




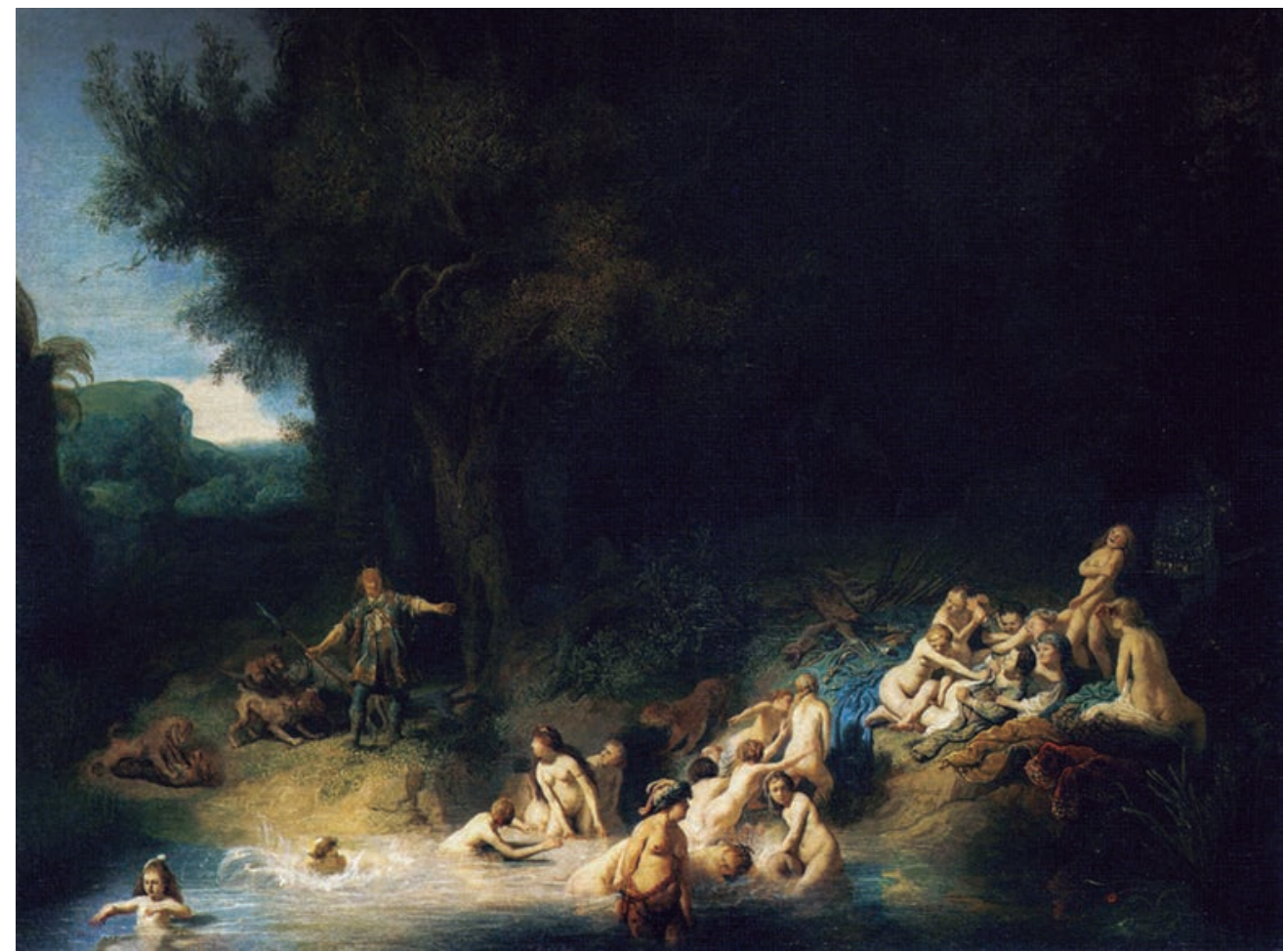

Figura 9. Historias de Diana, Rembrandt, 1634. Museum Wasserburg Anholt, Isselburg, Alemania

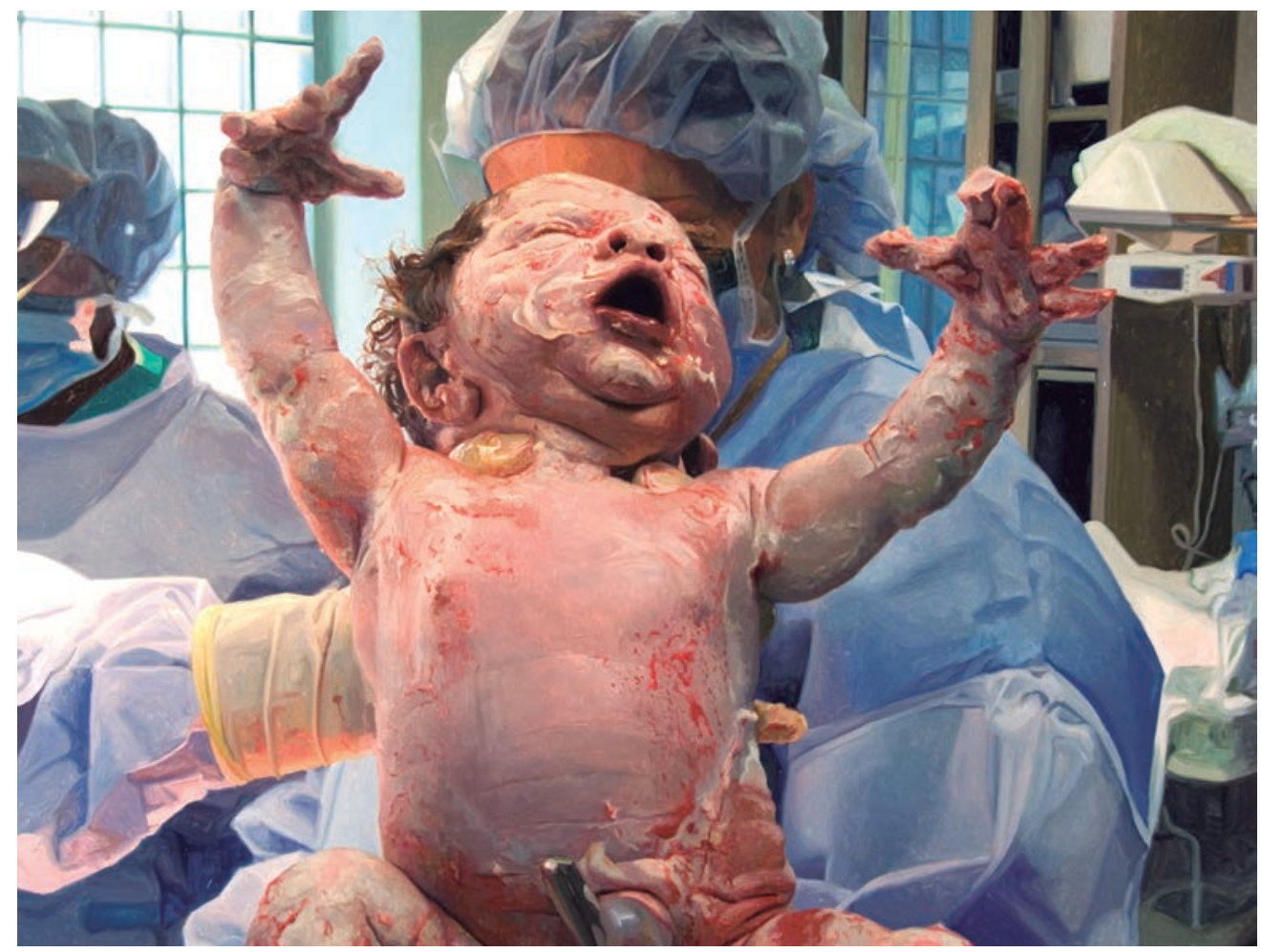

Figura 10. Baptism, Alyssa Monks 


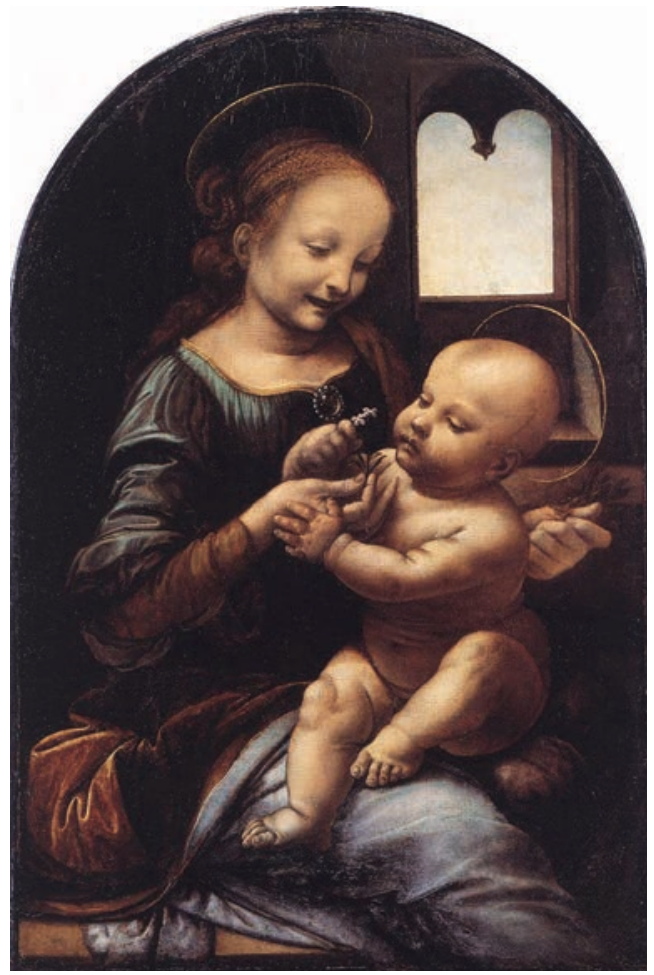

Figura 11. Madonna Benois, Leonardo Da Vinci, 1478-1482. Museo del Hermitage, San Petersburgo, Rusia

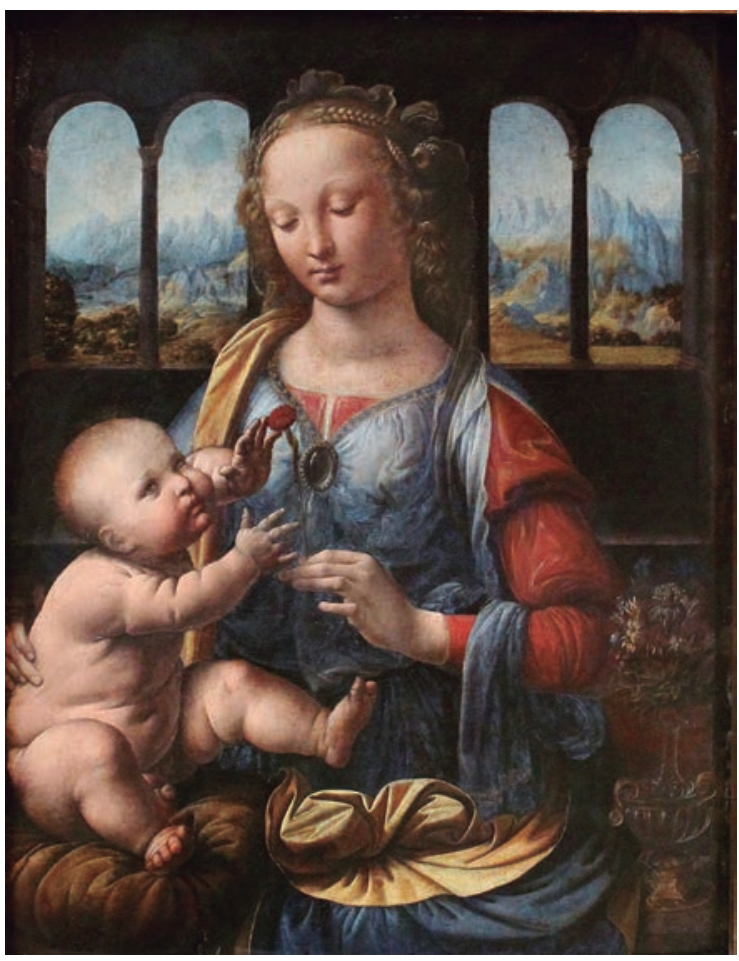

Figura 12. Virgen del clavel (Madonna del garofano),Leonardo da Vinci, 1470. Alte Pinakothek, Múnich, Alemania renacimiento, como Leonardo Da Vinci en la Madonna Benois, en la que, además, llama la atención la sonrisa maternal de la virgen "como una madre del común" con el tesoro en su regazo, expresión poco frecuente en las vírgenes... amén de su derrochador sentimental mirar (figura 11), y él mismo, en la Virgen del clavel que se exhibe en la Pinacoteca Antigua de Múnich (figura 12), y Raphael en el óleo sobre lienzo Madona de la rosa, en El Prado (figura 13).

En Chicos en la playa, del valenciano Joaquín Sorolla, bajo el estilo del luminismo, nos muestra los diversos tonos de las jóvenes pieles; de los aceitunados al aperlado con visos rosa, con la incidencia de la luz sobre ellas, mojadas, permitiendo casi palpar la firmeza del soporte muscular, dibujando con su reflejo la figura humana en el agua marina (figura 14).

El gran renacentista Rafael Sanzio, en su Retrato de una joven -La Fornarina-transmite la belleza de la piel juvenil en los límites de la perfección, de la luminosidad, de la vitalidad, de la delicadeza, como se evidencia en el primor de sus pezones; es tan maravillosa que el autor delicadamente puso el tul sobre su abdomen pero permitiéndonos apreciar a través de él hasta la cicatriz umbilical (figura 15). El francés Édouard Manet, uno de los iniciadores del Impresionismo, en su última creación Un bar del Folies-Bergère,

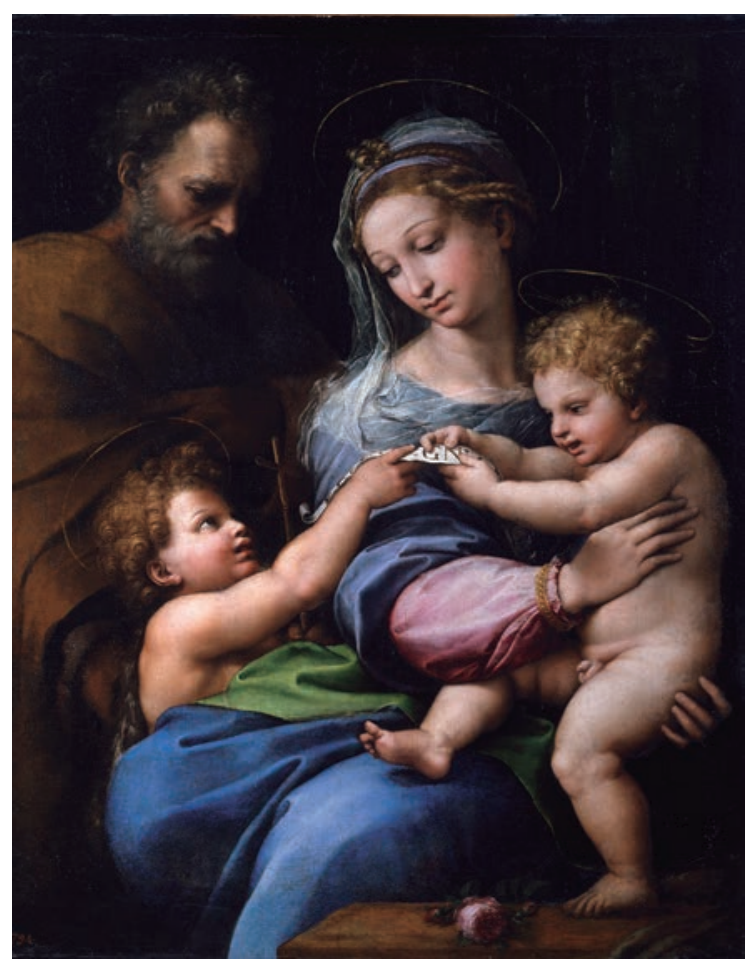

Figura 13. Madonna de la rosa, Raphael, 1517. Museo del Prado, Madrid, España 


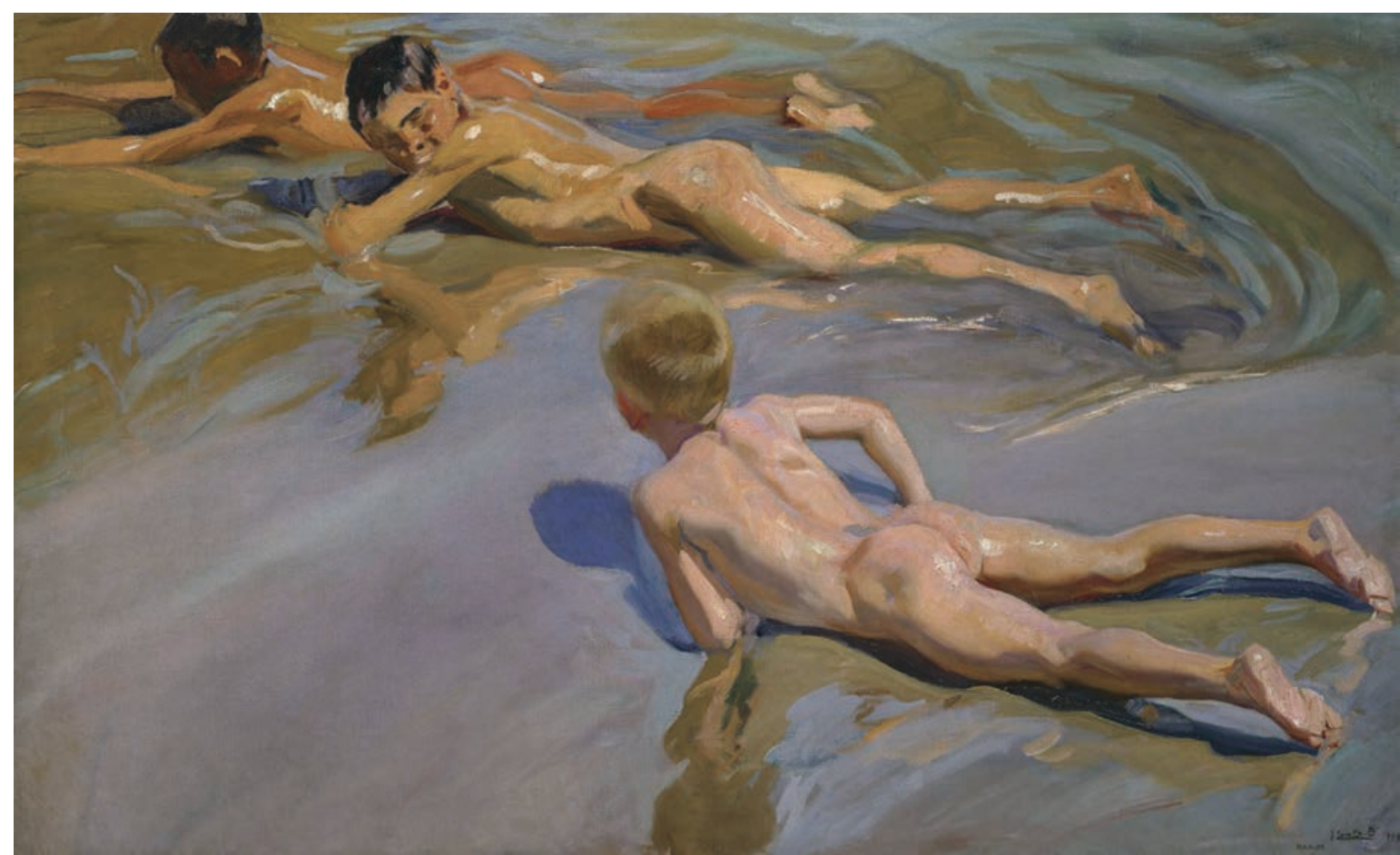

Figura 14. Chicos en la playa, Joaquín Sorolla y Bastida, 1910. Museo del Prado, Madrid, España

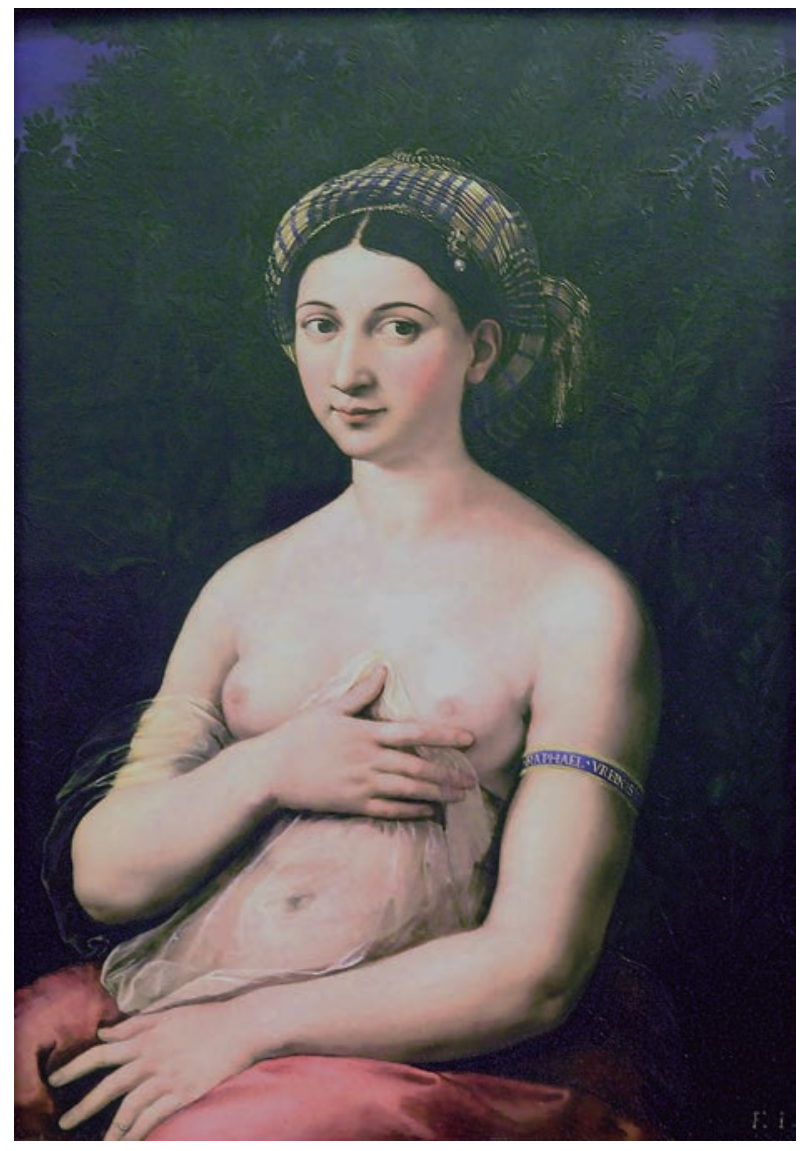

..."la belleza de la piel juvenil en los límites de la perfección, de la luminosidad, de la vitalidad, de la delicadeza, como se evidencia en el primor de sus pezones; es tan maravillosa que el autor delicadamente puso el tul sobre su abdomen pero permitiéndonos apreciar a través de él hasta la cicatriz umbilical"

Figura 15. La Fornarina (retrato de una joven), Rafael Sanzio, 1518-1519. Galería Nacional de Arte Antiguo, Palacio Barberini, Roma, Italia 


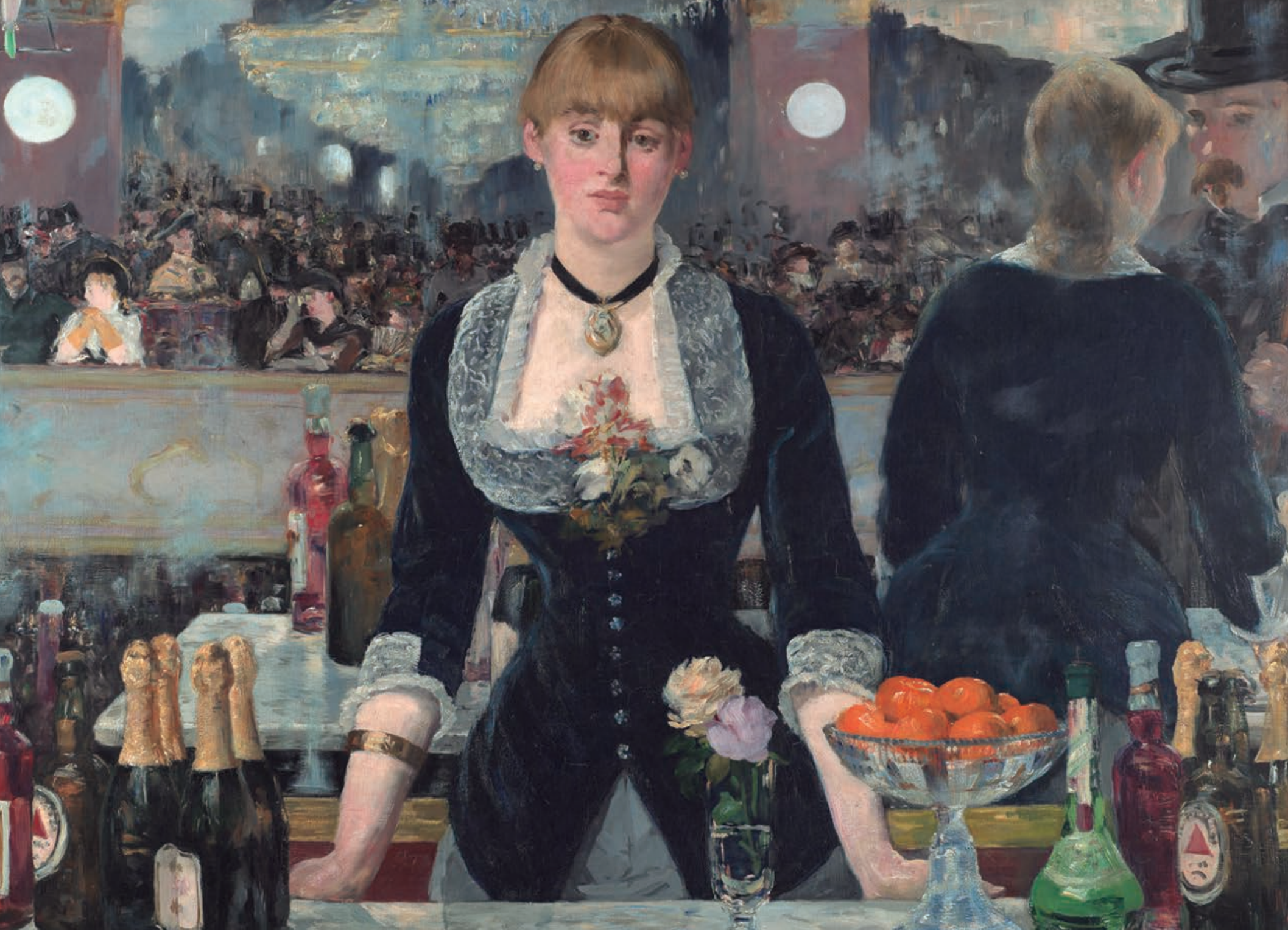

Figura 16. Un bar del Folies-Bergère, Édouard Manet, 1882. Courtauld Institute of Art, Londres, Inglaterra

presentado en el Salón de París, nos ilustra la belleza encantadora de la piel de la joven con sus mejillas carmín, ella impecable, en consonancia con las flores, frutas y botellas que anteceden su figura, teniendo como fondo la vivencia cotidiana del bar claramente impresionista (figura 16).

La piel en la adultez se robustece en belleza, colorido y formas, como de manera magistral lo plasmó Botticelli en El nacimiento de Venus (figura 17). La obra es casi un poema de la belleza de la piel de la mujer adulta. Las líneas y los tonos trazan y realzan cada uno de los primorosos contornos con magistral sutileza y finura, engalanada por su abundante y primorosa cabellera dorada, llena de vida, ondeante tras las caricias de los vientos ${ }^{6}$.

Hacia el final del sendero, los tiempos idos, al dejar impregnadas las vivencias en el ser, marcan cual huellas digitales el tegumento y generan en él cambios que lo acicalan, como el pincel de Durero forjó con suavidad y bello realismo cada detalle de esta hermosa, respetable y venerable etapa de la vida, en su San Felipe el Apóstol (figura 18) y en Anciana con monedero (figura 19).

Sin lugar a dudas, a lo largo de la existencia, por las razones propias de la fisiología humana, la piel modifica su aspecto y es, además, intervenida por los efectos ambientales y psicobiosociales, y claro está, por los embates del alma, para bien o para mal. Grien, en el siglo XVI, en Las tres edades de la mujer de la que hace caudal el Museo de Historia del Arte de Viena, ejemplifica la evolución. Muestra de qué manera la inocente párvula juguetea ajena al presente y al futuro, como al futuro también la joven, con la límpida blancura de su piel, la turgencia de sus pechos, la voluptuosidad primorosa de su abdomen y de sus muslos, admirándose en el espejo y pareciendo forastera al inexorable paso del tiempo que marca el reloj de arena; en cuanto a la anciana, con su decadente piel ya oscura y su angustioso mirar, intenta detenerlo de la mano de la parca, ésta, ya, con su piel hecha jirones, seca, apenas cubriendo con retazos la osamenta parda (figura 20).

En el albor del siglo XX, el modernista Klimt presenta de nuevo la temática de la evolución natural del hombre en Las tres edades de la vida, atesorado en la Galería Nacional de Arte Moderno en Roma (figura 21). Este nuevo estilo de alegoría del paso del tiempo nos muestra a la joven madre que 


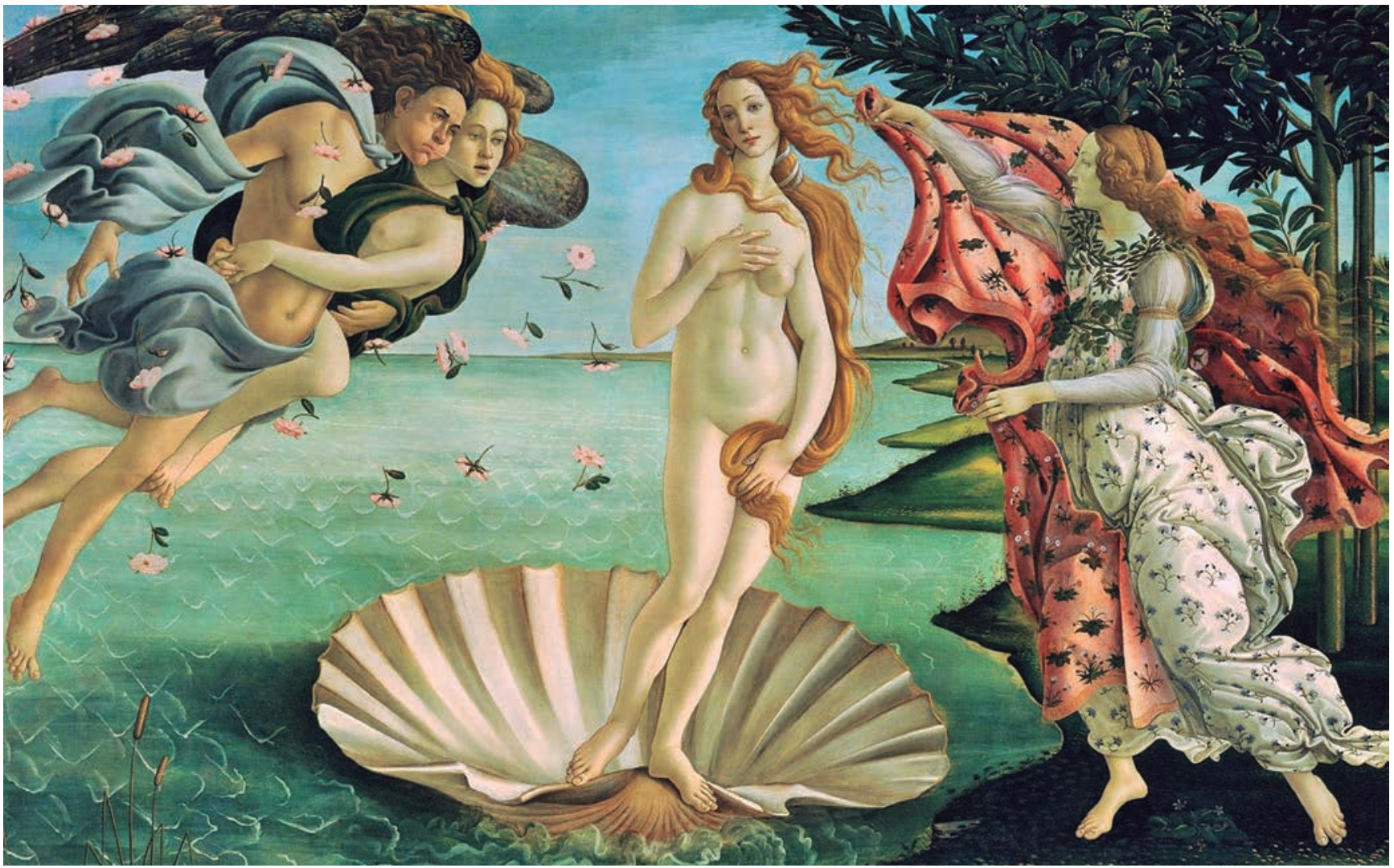

Figura 17. El nacimiento de Venus, Sandro Botticelli, 1484. Galería Uffizi, Florencia, Italia

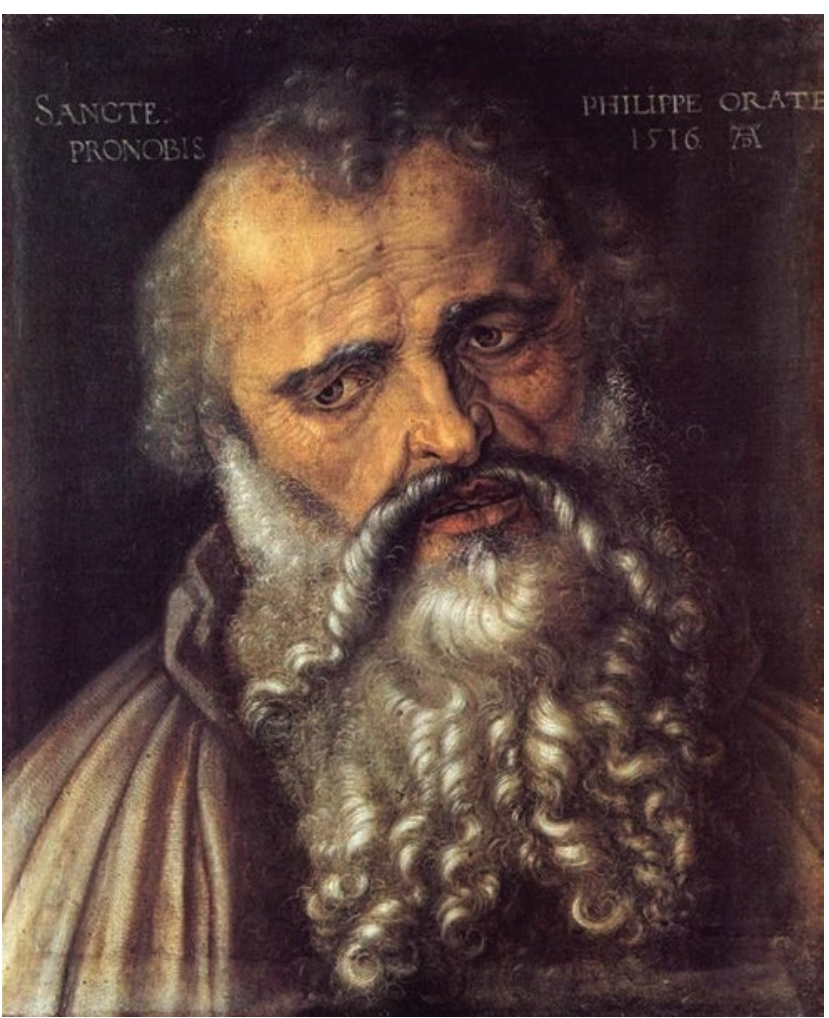

Figura 18. San Felipe el Apóstol, Alberto Durero, 1516. Galería Uffizi, Florencia, Italia

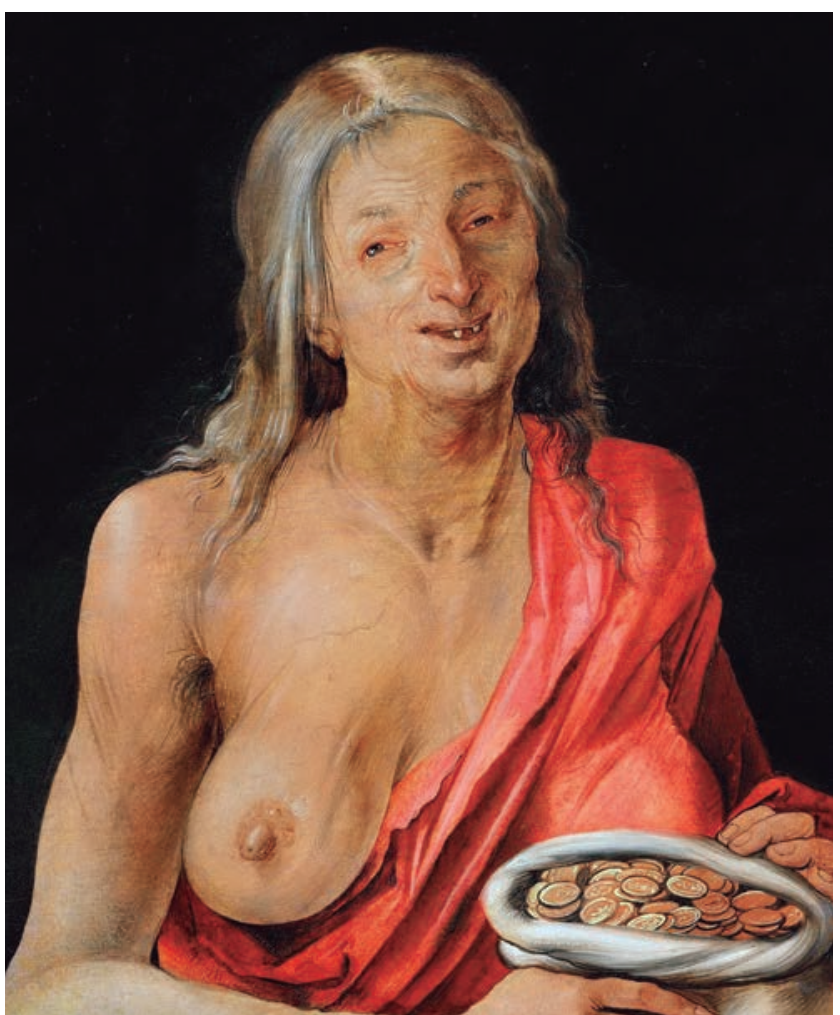

Figura 19. Anciana con monedero, Alberto Durero, 1507. Museo de Historia del Arte, Viena, Austria 


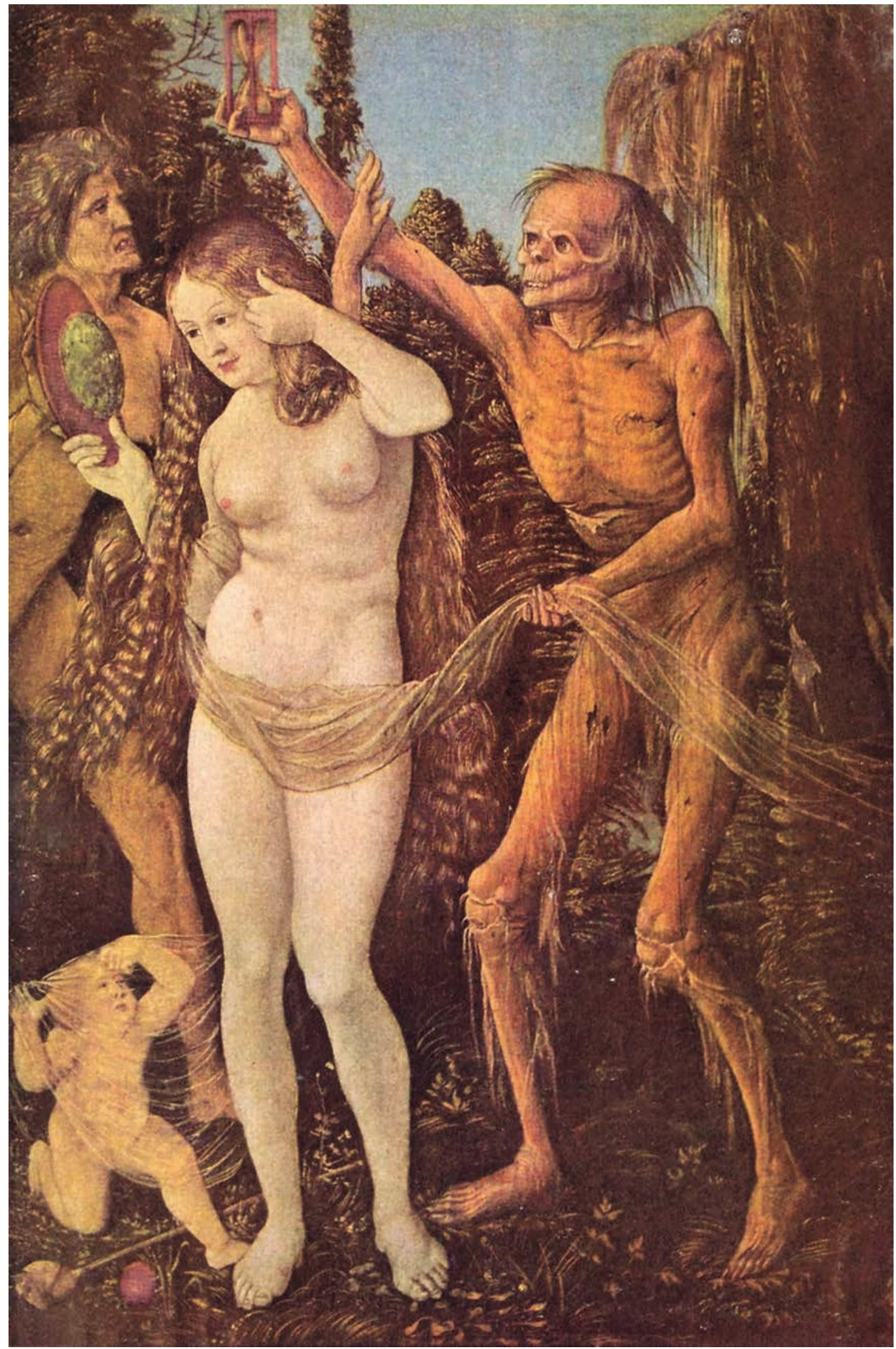

Figura 20. Las tres edades de la mujer, Hans Baldung -Grien o Grün-, 1510. Museo de Historia del Arte, Viena, Austria 


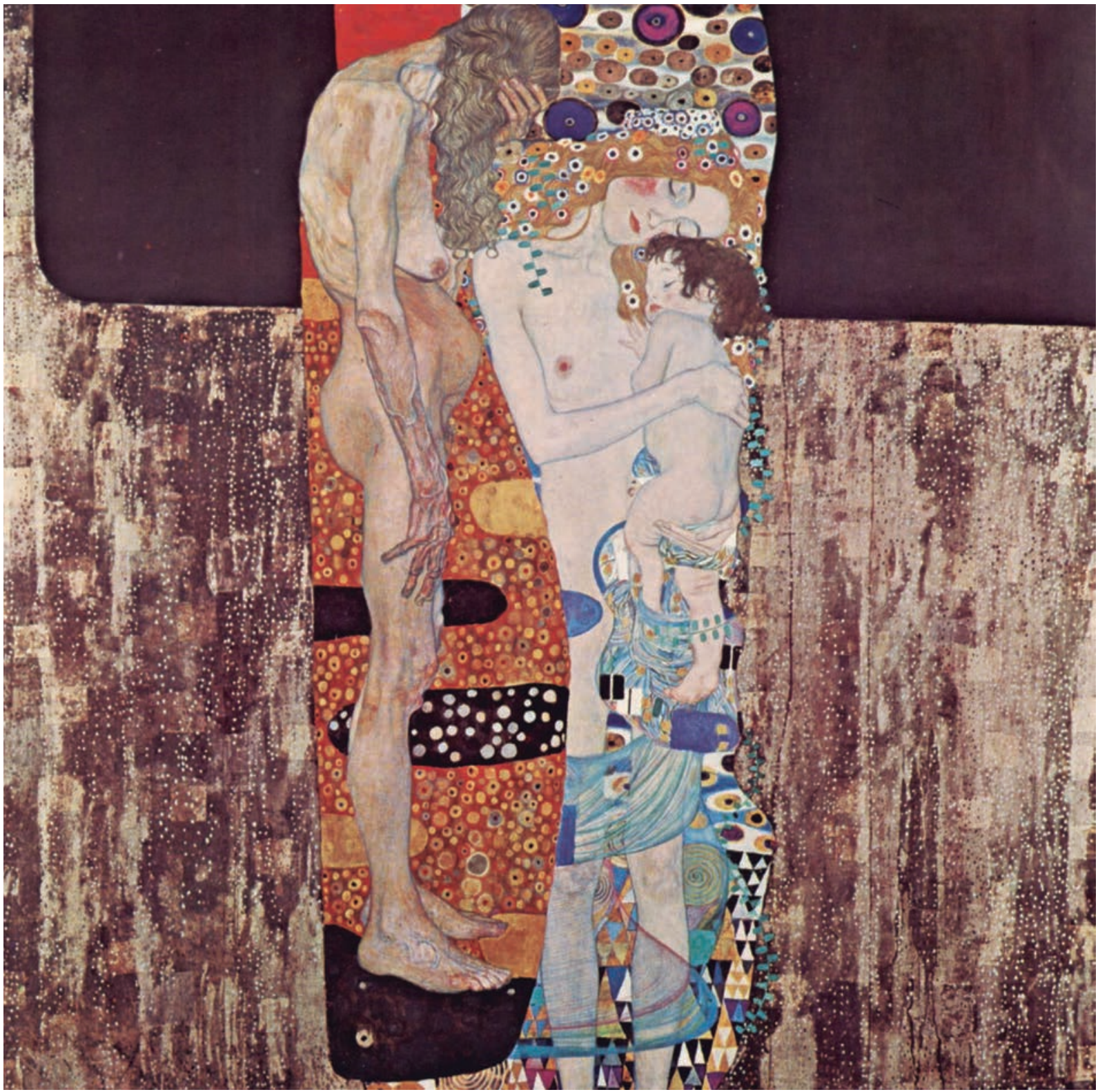

Figura 21. Las tres edades de la vida, Gustav Klimt, 1905. Galería Nacional de Arte Moderno, Roma, Italia

estrecha contra su pecho a su hija, las dos, plácidamente dormidas, sumidas en un universo de tranquilidad, en fuerte contraste con la anciana que oculta su rostro con su mano y su cenizo pelo, en cuanto enseña su decadencia anatómica que se trasparenta por su piel al tiempo que se resalta la tortuosidad voluptuosa de sus venas. El peso de los años se acumula en el seno péndulo de la abuela, en cuanto la joven madre exhibe la firmeza de los suyos mirando al frente.

Piel que en tu cadencioso trajinar improntas el camino de la vida...

\section{AGRADECIMIENTOS}

A la pintora estadounidense Allysa Monks por su generosidad para con el autor y por autorizar la reproducción de su obra para uso exclusivo de esta publicación mediante contrato firmado el 26 de diciembre de 2016. 


\section{REFERENCIAS}

1. Doña F. Siguiendo a Letamendi (blog). Fecha de consulta: 17 de noviembre de 2015. Disponible en: https:// letamendi.wordpress.com.

2. Faure M. La dermatología en la pintura. En: Wallach D, Tilles G, editores. La historia de la dermatología en Francia. Toulouse, Francia: Éditions Privat; 2002. p.741-7.

3. Meshberger FL. An interpretation of Michelangelo's Creation of Adam based on neuroanatomy. JAMA. 1990;264:1837-41.

4. Marqués SO. La piel en la pintura. Madrid: Reprofot, S.L.; 2009.

5. Liga Bíblica Internacional, editores. Biblia devocional de estudio. Antigua versión de Casiodoro de Reina (1569). Revisión de 1960. Crete, USA: Zondervan Corporation; 1986. p. 283

6. Arciniegas G. El mundo de la bella Simonetta. Segunda edición. Bogotá: Editorial Planeta;1990. 